
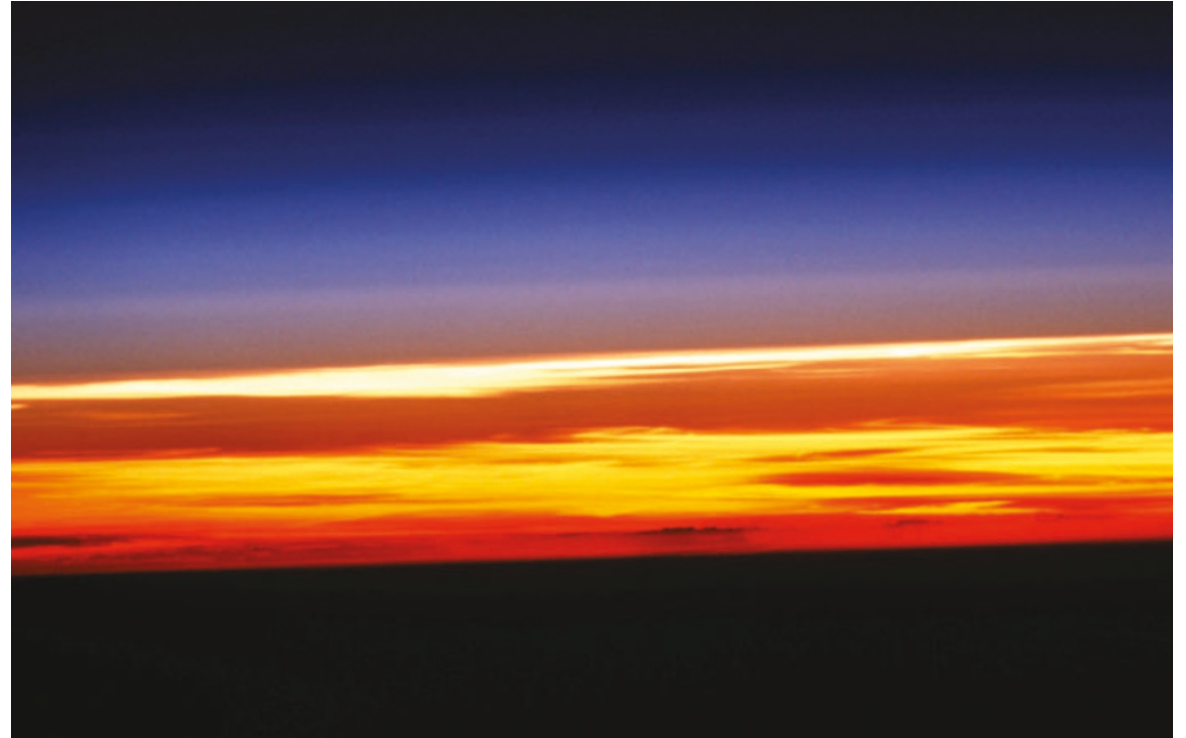

Sky high: cooling in the stratosphere influences temperature trends in the layer of atmosphere below.

\title{
Global warming anomaly may succumb to microwave study
}

Quirin Schiermeier

For years, climate researchers have struggled with an apparent discrepancy in the data on global warming: temperatures in the lower atmosphere have been rising far slower than models predict, given how fast the Earth's surface is heating.

The discrepancy has been central to the arguments of sceptics about global warming. But according to a study in this issue of Nature (see page 55) it can be explained by interactions between the troposphere - the first $11 \mathrm{~km}$ of the atmosphere - and the stratosphere above it.

In the study, a team from the University of Washington at Seattle and the Air Resources Laboratory of the National Oceanic and Atmospheric Administration (NOAA), based in Maryland, analysed microwave emissions from the atmosphere. The emissions were recorded between 1979 and 2001 by NOAA's polar orbiting satellites. The data can be used to deduce temperatures in different layers of the atmosphere. And the study finds that stratospheric cooling, a known effect of greenhouse gases, appears to account for discrepancies between temperature trends on the ground and in the troposphere.

The team, led by Qiang Fu, an atmospheric researcher at the University of Washington, subtracted the impact of such cooling from data on the stratosphere and performed a statistical analysis, which found temperature trends consistent with observed warming on the surface and the predictions of climate models.

The finding is "a stunningly elegant and accurate method of clarifying global trends", says Kevin Trenberth, head of the climate analysis section at the National Center for Atmospheric Research in Boulder, Colorado.
But it does not impress John Christy, director of the Earth System Science Center at the University of Alabama in Huntsville, whose work established the inconsistency between temperature trends on the surface and in the troposphere (Science 247, 1558-1662; 1990). "You cannot eliminate the stratosphericinfluence with statistical tools alone," he says. "If you want to know precisely what happens you need physical measurements." He says that Fu has overcorrected for the impact of the stratosphere in his analysis.

Other climate scientists welcomed the new findings. "This is the answer — I wish we had recognized it ourselves," says John Wallace, an atmospheric researcher also at the University of Washington, who chaired a 2000 survey on reconciling global warming discrepancies for the US National Academies.

The study should be noted by policymakers who justify lack of action on global warming by citing scientific uncertainty, says Wallace. But he is not optimistic about how many minds will be changed. "Single scientific discoveries have little impact in the political arena," he says. NOAA officials declined to comment on the political implications of the study.

The research comes just after a report from the Pew Center on Global Climate Change predicted that global warming could shrink the US economy.

But neither economic nor scientific analyses are likely to affect US climate change policy, says Henry Jacoby, director of the Massachusetts Institute of Technology's Joint Program on the Science and Policy of Global Change. "After the Kyoto fiasco, the US administration began to ask for advice from all sides," he says. "But unfortunately it has never taken the advice it received."

\section{Fatal fruit bat virus sparks epidemics in southern Asia}

Declan Butler

Television cameras may be few and far between in rural areas of Bangladesh, south Asia's poorest nation. But killer human viruses are recurrent there, and are quietly wreaking havoc.

An outbreak of the emerging Nipah virus in the Faridpur district of the country earlier this month infected 30 people and killed 18. That epidemic is one of several that have hit Bangladesh, Malaysia and Singapore since the virus was first discovered in 1998.

The Nipah virus and the related Australian Hendra virus form the Henipavirus genus within the paramyxovirus family. They cause high mortality - two in every five infected people die - but pose less of a global risk than more notorious viruses such as SARS (severe acute respiratory syndrome). That is because infection requires close contact with the animal host, the Pteropus fruit bat, and does not seem to pass from human to human.

The virus was discovered in Malaysia, during a 1998 outbreak in the village of Nipah that killed 105 people. The transmission route of the virus in Bangladesh seems different from outbreaks elsewhere, however, says Marie-Claude Georges-Courbot, an expert on the disease at the Pasteur Institute in Lyon.

The exact mechanism of transmission is poorly understood, says GeorgesCourbot. The Malaysian epidemic arose in humans following an outbreak in pigs that had come into contact with bat urine. But the outbreaks in Bangladesh - one in February killed 17 people appear to have been caused by children who had direct contact with batcontaminated fruit, she says.

The symptoms of the disease in Bangladesh are also different, being largely neurological; the Malaysian outbreak caused pulmonary complications.

Georges-Courbot is part of a team of French and Malaysian researchers who earlier this year reported that golden hamsters could be protected from Nipah by vaccinia viruses. The team used vaccinia to express two proteins that the Nipah virus uses to enter human cells. The research also showed that serum from vaccinated hamsters prevented onset of the disease in others. This suggests the possibility of an immunotherapeutic approach to treating Nipah, and perhaps its Hendra cousin. 